\begin{tabular}{|l|l|l|}
\hline \multicolumn{2}{|c|}{ PublisherInfo } \\
\hline \hline PublisherName & $:$ & BioMed Central \\
\hline \hline PublisherLocation & $:$ & London \\
\hline \hline PublisherImprintName & $:$ & BioMed Central \\
\hline \hline
\end{tabular}

\title{
Double-duplication evolution
}

\begin{tabular}{|l|l|l||}
\hline \multicolumn{2}{|c|}{ ArticleInfo } \\
\hline \hline ArticleID & $:$ & 3760 \\
\hline \hline ArticleDOI & $:$ & $10.1186 /$ gb-spotlight-20000906-02 \\
\hline \hline ArticleCitationID & $:$ & spotlight-20000906-02 \\
\hline \hline ArticleSequenceNumber & $:$ & 197 \\
\hline \hline ArticleCategory & $:$ & Research news \\
\hline ArticleFirstPage & $:$ & 1 \\
\hline \hline ArticleLastPage & $:$ & 2 \\
\hline \hline & $:$ & RegistrationDate : 2000-09-06 \\
ArticleHistory & $:$ & OnlineDate \\
\hline \hline ArticleCopyright & $:$ & BioMed Central Ltd2000-09-06 \\
\hline \hline ArticleGrants & $:$ & \\
\hline \hline ArticleContext & $:$ & 130591111 \\
\hline \hline
\end{tabular}




\section{William Wells}

Email:wells@biotext.com

In the 1 September Science Lang et al. argue that two single-domain biosynthetic enzymes appear to have evolved from gene duplication, followed by fusion, followed by a second gene duplication (Science 2000, 289:1546-1550). Both of the proteins, HisA and HisF, can be broken down into two half beta/ alpha barrels. The four half barrels can be superimposed on each other, revealing $22 \%$ identical or similar residues. As both enzymes bind biphosphate substrates, each half barrel has a phosphate-binding motif, and HisF even exhibits limited HisA catalytic activity. Lang et al. propose that an ancestral protein motif was duplicated and fused to produce the HisA isomerase enzyme, before a second duplication and further evolution yielded the more complex HisF synthase activity.

\section{References}

1. Science magazine, [http://www.sciencemag.org/]

2. Three-dimensional profiles from residue-pair preferences: identification of sequences with beta/ alpha-barrel fold. 